\title{
Activation of extrasynaptic kainate receptors drives hilar mossy cell activity
}

Abbreviated title: Extrasynaptic KARs in mossy cells

4

Czarina Ramos $^{1 *}$, Stefano Lutzu ${ }^{1 *}$, Miwako Yamasaki ${ }^{2}$, Yuchio Yanagawa $^{3}$, Kenji Sakimura ${ }^{4}$, Susumu Tomita $^{5}$, Masahiko Watanabe ${ }^{2}$ and Pablo E. Castillo ${ }^{1,6 \neq}$

${ }^{1}$ Dominick P. Purpura Department of Neuroscience Albert Einstein College of Medicine, 1300 Morris Park Avenue Bronx, NY, 10461, USA.

${ }^{2}$ Department of Anatomy, Faculty of Medicine, Hokkaido University, Sapporo 060-8638, Japan.

${ }^{3}$ Department of Genetic and Behavioral Neuroscience, Gunma University Graduate School of Medicine, Maebashi 371-8511, Japan.

${ }^{4}$ Department of Cellular Neurobiology, Brain Research Institute, Niigata University, Niigata 9518585, Japan.

${ }^{5}$ Department of Cellular and Molecular Physiology, Department of Neuroscience, and Kavli Institute for Neuroscience, Yale University School of Medicine, New Haven, Connecticut 06520, USA.

${ }^{6}$ Department of Psychiatry and Behavioral Sciences, Albert Einstein College of Medicine, 1300 Morris Park Avenue Bronx, NY, 10461, USA.

*These authors contributed equally to this work.

${ }^{\ddagger}$ To whom correspondence should be addressed:

\author{
Pablo E. Castillo, MD/PhD \\ Dominick P. Purpura Department of Neuroscience \\ Albert Einstein College of Medicine \\ 1410 Pelham Parkway South \\ Kennedy Center, Room 703 \\ Bronx, NY 10461, USA \\ Email: pablo.castillo@einsteinmed.org
}

The authors declare no conflict of interest.

Acknowledgments: We thank the members of the Castillo lab (in particular Dr. Kaoutsar Nasrallah) for constructive feedback and for reading and commenting the manuscript. This research was supported by the National Institutes of Health: R01-NS113600, R01-MH116673 and R01MH125772 to P.E.C; Grant-in-Aid for Specially Promoted Research from Japan Society for the Promotion of Science (JSPS) (20H05628) and for Scientific Research B from Japan Society for the Promotion of Science (JSPS) (21H02589) to M.W.; JSPS KAKENHI Grants (17H0631310 and 20H03410) to M.Y.

Number of pages: 24

Number of figures: 6

Number of words: Abstract (241), Introduction (699) and Discussion (1,317) 


\section{Abstract:}

2 Mossy cells (MCs) of the dentate gyrus (DG) are key components of an excitatory associative 3 circuit established by reciprocal connections with dentate granule cells (GCs). MCs are implicated 4 in place field encoding, pattern separation and novelty detection, as well as in brain disorders 5 such as temporal lobe epilepsy and depression. Despite their functional relevance, little is known 6 about the determinants that control MC activity. Here, we examined whether MCs express 7 functional kainate receptors (KARs), a subtype of glutamate receptors involved in neuronal 8 development, synaptic transmission and epilepsy. Using mouse hippocampal slices, we found 9 that bath application of submicromolar and micromolar concentrations of the KAR agonist kainic acid induced inward currents and robust MC firing. These effects were abolished in GluK2 KO mice, indicating the presence of functional GluK2-containing KARs in MCs. In contrast to CA3 pyramidal cells, which are structurally and functionally similar to MCs, and express synaptic KARs at mossy fiber (MF) inputs (i.e., GC axons), we found no evidence for KAR-mediated transmission at MF-MC synapses, indicating that most KARs at MCs are extrasynaptic. Immunofluorescence and immunoelectron microscopy analyses confirmed the extrasynaptic localization of GluK2containing KARs in MCs. Finally, blocking glutamate transporters, a manipulation that increases extracellular levels of endogenous glutamate, was sufficient to induce KAR-mediated inward currents in MCs, suggesting that MC-KARs can be activated by increases in ambient glutamate. Our findings provide the first direct evidence of functional extrasynaptic KARs at a critical excitatory neuron of the hippocampus.

\section{Significance Statement:}

Hilar mossy cells (MCs) are an understudied population of hippocampal neurons that form an excitatory loop with dentate granule cells. MCs have been implicated in pattern separation, spatial navigation, and epilepsy. Despite their importance in hippocampal function and disease, little is known about how MC activity is recruited. Here, we show for the first time that MCs express

27 extrasynaptic kainate receptors (KARs), a subtype of glutamate receptors critically involved in 28 neuronal function and epilepsy. While we found no evidence for synaptic KARs in MCs, KAR 29 activation induced strong action potential firing of $\mathrm{MCs}$, raising the possibility that extracellular 30 KARs regulate MC excitability in vivo and may also promote dentate gyrus hyperexcitability and 31 epileptogenesis. 


\section{Introduction}

Hilar mossy cells (MCs) in the hilus of the dentate gyrus (DG) are major excitatory neurons that widely project onto dentate granule cells (GCs) to control their activity (Buckmaster and Schwartzkroin, 1994; Hashimotodani et al., 2017; Scharfman, 2018; Botterill et al., 2019). Within the DG, MCs form an associative network with GCs, in which MCs receive extensive convergent excitatory inputs from GCs (Patton and McNaughton, 1995; Acsady et al., 1998; Buckmaster and Jongen-Relo, 1999; Ribak and Shapiro, 2007) and then send excitatory feedback projections to up to $\sim 30,000 \mathrm{GCs}$ along the dorsoventral axis of the ipsi- and contralateral hippocampus (Ribak et al., 1985; Frotscher et al., 1991; Buckmaster et al., 1996; Wenzel et al., 1997). Thus, the activity of a single MC can significantly impact the activity of numerous GCs, and ultimately, DG-CA3 information transfer. MCs contribute to hippocampal-dependent computations and behaviors such as pattern separation, spatial navigation and other cognitive functions such as novelty detection (Duffy et al., 2013; Danielson et al., 2017; GoodSmith et al., 2017; Senzai and Buzsaki, 2017; Fredes et al., 2021). In addition, aberrant MC function has been linked to brain disorders such as temporal lobe epilepsy (TLE), depression, anxiety and schizophrenia (Scharfman, 2016). Despite the important role that MCs play in brain function and disease, the mechanisms through which MC activity is recruited are still largely unexplored.

MCs share many structural and functional properties with CA3 pyramidal cells. Both CA3 pyramidal cells and MCs receive in their proximal dendrites a major excitatory input from GCs via the mossy fibers axons (MF), which impinge on complex spines called thorny excrescences (TEs) via giant presynaptic boutons (Amaral and Dent, 1981; Acsady et al., 1998). Functionally, the MFto-MCs (MF-MC) synapse expresses robust forms of short- and long-term plasticity (Lysetskiy et al., 2005), similar to those reported at the MF-to-CA3 pyramidal cell (MF-CA3) synapse (Henze et al., 2002; Nicoll and Schmitz, 2005). In addition, glutamate release at both synapses is inhibited by activation of presynaptic group $2 / 3$ metabotropic glutamate receptors (mGluR2/3) (Kamiya et al., 1996; Lysetskiy et al., 2005). While excitatory transmission is mainly mediated by AMPA and NMDA ionotropic glutamate receptors, a slow component of MF-CA3 synaptic transmission is mediated by kainate receptors (KARs) (Castillo et al., 1997). A similar, albeit modest KARmediated component has recently been reported at the MF-MC synapse (Hedrick et al., 2017). KARs are ionotropic glutamate receptors expressed in several brain areas, which have been implicated in neuronal development, neuronal excitability, synaptic transmission and plasticity 
1 (Lerma and Marques, 2013). In vivo injection of the KAR agonist kainic acid (KA), a widely used

2 animal model of TLE (Rusina et al., 2021), strongly activates CA3 pyramidal neurons (Westbrook

3 and Lothman, 1983; Crepel and Mulle, 2015), and also leads to extensive MCs loss (Buckmaster

4 and Jongen-Relo, 1999; Sloviter et al., 2003), suggesting that MCs are particularly sensitive to

5 the activation of KARs. Intriguingly, while KAR-mediated responses are much weaker at MF-MC

6 synapses (Hedrick et al., 2017) than at MF-CA3 synapses (Castillo et al., 1997; Mulle et al., 1998),

7 transcriptome profiling revealed that MCs and CA3 pyramidal cells display comparable levels of

8 transcripts for the functional KAR subunit GluK2 (Cembrowski et al., 2016), raising the possibility

9 that KARs may have additional roles at MCs.

11 In this study, we combined in vitro electrophysiology in acute rat and mouse hippocampal slices,

12 of wild type and GluK2 knockout (KO) mice, with anatomical approaches such as 13 immunofluorescence and immunoelectron microscopy, to determine the role and subcellular 14 localization of KARs in MCs. We found that submicromolar and micromolar concentrations KA 15 induced robust inward currents and strong MC firing, and both effects were absent in GluK2 KO 16 mice. Surprisingly, unlike in CA3 pyramidal neurons (Castillo et al., 1997), MF activation did not 17 elicit any measurable KAR-mediated synaptic response in MCs. Consistent with these 18 observations, immunofluorescence and immunoelectron microscopy revealed GluK2-containing 19 KARs in the soma and dendrites of MCs, but nearly absent from MC TEs. Lastly, blocking 20 glutamate uptake by excitatory amino-acid transporters (EAATs) elicited KAR-mediated inward 21 currents in MCs. Altogether, our findings support the notion that MCs express functional 22 extrasynaptic KARs whose activation by pharmacological agents (e.g., KA) and ambient 23 glutamate may play an important role in engaging the GC-MC-GC recurrent circuit.

\section{METHODS}

\section{Animals}

27 Experiments were performed on postnatal Sprague-Dawley rats (P18-P28) of both sexes and C57BL/6 mice of both sexes for electrophysiological recordings. Animals were group-housed in a standard 12h light/12h dark cycle. WT, GluK2 KO, and GAD67 $7^{+/ G F P}$ mice (Tamamaki et al., 2003); were obtained from Dr. Yanagawa, Gunma University, Japan. Handling and use of animals 
1 College of Medicine, at Yale University and at the Faculty of Medicine at Hokkaido University and

2 in accordance with guidelines provided by the National Institutes of Health.

3

\section{Hippocampal Slice Preparation}

Animals were deeply anesthetized with isoflurane and then decapitated. The brain was then rapidly removed from the skull and then hippocampi were dissected. Hippocampi were included in agar supports and acute transverse hippocampal slices (400 $\mu \mathrm{m}$ thick for Sprague-Dawley rats, $300 \mu \mathrm{m}$ for C57BL/6 mice) were cut using a VT1200s vibratome (Leica Microsystems Co.) in a sucrose-based cutting solution containing (in $\mathrm{mM}$ ): 215 sucrose, $2.5 \mathrm{KCl}, 26 \mathrm{NaHCO}_{3}, 1.6$ $\mathrm{NaH}_{2} \mathrm{PO}_{4}, 1 \mathrm{CaCl}_{2}, 4 \mathrm{MgCl}_{2}, 4 \mathrm{MgSO}_{4}$, and $20 \mathrm{D}$-glucose. After 15 mins in recovery postsectioning, the solution was replaced by extracellular artificial cerebrospinal fluid (ACSF) recording solution containing (in $\mathrm{mM}$ ): $124 \mathrm{NaCl}, 2.5 \mathrm{KCl}, 26 \mathrm{NaHCO}_{3}, 1 \mathrm{NaH}_{2} \mathrm{PO}_{4}, 2.5 \mathrm{CaCl}_{2}, 1.3$ $\mathrm{MgSO}_{4}$, and $10 \mathrm{D}$-glucose. Slices were incubated for a minimum of 30 minutes in the ACSF before recording. Solutions were equilibrated with $95 \% \mathrm{O}_{2}$ and $5 \% \mathrm{CO}_{2}(\mathrm{pH} 7.4)$.

\section{Electrophysiology}

All experiments were performed in a submersion-type recording chamber perfused at $\sim 2 \mathrm{~mL} \mathrm{~min}^{-}$ 1 , at $28 \pm 1^{\circ} \mathrm{C}$, except those in Fig. 6 where temperature was raised to $34^{\circ} \mathrm{C} \pm 1^{\circ} \mathrm{C}$. Whole-cell patch clamp recordings using a Multiclamp 700A amplifier (Molecular Devices) were performed from MCs and GCs in voltage-clamp $\left(\mathrm{V}_{\text {hold }}-60 \mathrm{mV}\right)$, or in current-clamp configuration $\left(\mathrm{V}_{\text {rest }} \sim-65\right.$ $\mathrm{mV}$ ) using borosilicate pipette electrodes ( 3-4 M $\Omega$ ). Recordings were performed using a $\mathrm{K}^{+}-$ based internal solution containing (in $\mathrm{mM}$ ): $135 \mathrm{KMeSO}_{4}, 5 \mathrm{KCl}, 1 \mathrm{CaCl}_{2}, 5 \mathrm{NaOH}, 10 \mathrm{HEPES}, 5$ MgATP, $0.4 \mathrm{Na}_{3}$ GTP, 5 EGTA, 10 D-glucose, pH 7.2 (280-290 mOsm). In some recordings we also employed a $\mathrm{Cs}^{+}$-based internal solution containing (in $\mathrm{mM}$ ): $131 \mathrm{Cs}$-gluconate, $8 \mathrm{NaCl}, 1$ $\mathrm{CaCl}_{2}, 10$ EGTA, 10 D-glucose and 10 HEPES, pH 7.2 (285-290 mOsm). Series resistance ( 7$25 \mathrm{M} \Omega$ ) was monitored throughout all experiments with a $-5 \mathrm{mV}, 80 \mathrm{~ms}$ voltage step, and cells that exhibited a significant change (>20\%) were excluded from analysis.

MCs were identified using previously established criteria (Larimer and Strowbridge, 2008). Specifically, we measured firing properties and membrane time constant by injection of a step of depolarizing current while in current-clamp configuration. Cells were confirmed as MCs by exhibiting elevated spontaneous synaptic activity, little to no afterhyperpolarization and non-burst 
1 firing patterns upon depolarizing pulses (5s duration, 60-120 pA). Additional confirmation was

2 performed post-hoc through morphological analysis of biocytin-filled cells where MCs were

3 identified by the presence of distinctive complex TEs in their proximal dendrites. To isolate KAR-

4 mediated currents and EPSCs, we bath applied a cocktail of antagonists which included:

5 LY303070 $(15 \mu \mathrm{M})$ or GYKI 53655 (GYKI - $30 \mu \mathrm{M})$, D-APV $(25 \mu \mathrm{M})$, picrotoxin $(50 \mu \mathrm{M})$ and

6 CGP35348 $(3 \mu \mathrm{M})$ to block AMPA, NMDA, GABA and $\mathrm{GABA}_{B}$ receptors, respectively. The

7 cocktail was applied right after the target cell was identified as a MC. For the isolation of KAR-

8 EPSC, we first monitored AMPAR-EPSCs in presence of the above specified cocktail, without

9 LY303070, which was bath applied after a stable baseline was acquired.

To evoke MF synaptic responses in MCs and CA3 pyramidal cells, a bipolar stimulating thetaglass pipette was filled with ACSF and placed in the subgranular zone of the DG. Only EPSCs that showed $<2 \mathrm{~ms} 20-80 \%$ rise time and robust paired-pulse facilitation (EPSC2/EPSC1 > 2) were considered MF-derived and included in the analysis.

To increase the probability of detecting a KAR-mediated EPSC, we delivered two stimuli (5 ms inter-stimulus interval, $100 \mu$ s duration, $\sim 100 \mu \mathrm{A}$ amplitude), using a stimulus isolator unit (Isoflex, AMPI). Typically, stimulation was adjusted to obtain comparable magnitude synaptic responses across experiments.

\section{Data analysis for electrophysiology experiments}

Electrophysiological data were acquired at $5 \mathrm{kHz}$ filtered at $2.4 \mathrm{kHz}$ and analyzed using custommade software for IgorPro (Wavemetrics Inc.). The change in the holding current ( $\Delta$ l holding) was calculated by subtracting the baseline holding current value (average of $50 \mathrm{~s}$ before KA application) from the average holding current post-drug application (average $50 \mathrm{~s}$ before washout). To calculate firing rate in the current clamp configuration, spikes were detected using a custom-made MatLab script, which detected all voltage increases above a threshold value established by the experimenter (i.e., $0 \mathrm{mV}$ ). When $3 \mu \mathrm{M} \mathrm{KA}$ was used to depolarize MCs, the peak of the action potentials gradually decreased (likely due to inactivation of voltage-gated sodium channels) and became undistinguishable from spontaneous activity. This led to an underestimation of the effect of $3 \mu \mathrm{M} \mathrm{KA}$ on MCs firing. Firing rate was quantified as number of spikes per second. 


\section{Reagents}

2 Reagents were bath applied following dilution into ACSF from stock solutions stored at $-20^{\circ} \mathrm{C}$ 3 prepared in water or DMSO, depending on the manufacturer's recommendation. The final DMSO 4 concentration was $<0.01 \%$ total volume. All chemicals and drugs used for the electrophysiology 5 experiments were purchased from Sigma-Aldrich (St. Louis, MO, USA) except NBQX, CGP6 55845, DCG-IV, and GYKI 53655, which were obtained from Tocris-Cookson (Minneapolis, MN, 7 USA), and tetrodotoxin, which was obtained from HelloBio (Inc, Princeton, NJ). LY 303070 was obtained from ABX advanced biochemical compounds (Radeberg, Germany).

\section{Quantification and statistical analysis.}

11 Statistical analysis was performed using OriginPro software (OriginLab). The normality of 12 distributions was assessed using the Shapiro-Wilk test. In normal distributions, Student's unpaired 13 and paired t Tests were used to assess between-group and within-group differences, respectively. 14 The non-parametric paired sample Wilcoxon signed rank test and Mann-Whitney's $U$ test were 15 used in non-normal distributions. Statistical significance was set to $p<0.05$ (*** indicates $p<$ $160.001,{ }^{* *}$ indications $p<0.01$, and ${ }^{*}$ indicates $\left.p<0.05\right)$. All values are reported as the mean \pm SEM.

\section{Fixation and sections}

20 We used glyoxal fixative containing $9 \%$ glyoxal and $8 \%$ acetic acid ( $/ \mathrm{v}, \mathrm{pH} 4.0$ adjusted with $5 \mathrm{~N}$ $21 \mathrm{NaOH}$ ), which is modified from the original glyoxal fixative (Richter et al., 2018). Under deep pentobarbital anesthesia (100 mg/kg body weight, i.p.), mice were fixed by transcardial perfusion with $\sim 60 \mathrm{ml}$ of glyoxal solution for $10 \mathrm{~min}$ at room temperature. Brains were postfixed in the same fixative for $3 \mathrm{~h}$ and cryoprotected with $30 \%$ sucrose in $0.1 \mathrm{M} \mathrm{PB}(\mathrm{pH} 7.2)$ for $2 \mathrm{~d}$. For immunofluorescence and immunoelectron microscopy, 50- $\mu$ m-thick coronal sections through the ventral hippocampus (3.0-3.7 mm posterior to Bregma) were prepared on a cryostat (CM1900; Leica Microsystems) and subjected to free-floating incubation.

\section{Antibodies}

We used the following antibodies: mouse anti-calretinin (MAB1568, Millipore; RRID, AB_94259), goat anti-EGFP (Takasaki et al., 2010)(AB_2571574), rabbit anti-GluK2/3 (Straub et al., 2011), 
1 guinea pig anti-Neto1(Straub et al., 2011), and guinea pig anti-PSD95 (Fukaya and Watanabe,

2 2000)(AB_2571612).

3

\section{Immunofluorescence}

All immunohistochemical procedures for immunofluorescence were performed at room temperature and PBS containing $0.1 \%$ Triton-X100 was used as a dilution and washing buffer. Sections were incubated with 10\% normal donkey serum for $20 \mathrm{~min}$, a mixture of primary antibodies overnight ( $1 \mu \mathrm{g} / \mathrm{ml}$ each), and a mixture of Alexa Fluor 405-, 488-, 647-, or Cy3-labeled species-specific secondary antibodies for $2 \mathrm{~h}$ at a dilution of 1:200 (Invitrogen; Jackson ImmunoResearch). To avoid cross talk between multiple fluorophores, images were taken with a confocal laser-scanning microscope equipped with 405-, 473-, 559-, and 647-nm diode laser lines, and UPLSAPO 10× (NA, 0.4), and PLAPON 60×OSC2 (NA, 1.4; oil immersion) objective lenses (FV1200, Olympus). Image and pinhole size were $800 \times 800$ pixels and 1 airy unit, respectively. To compare genotypic and regional difference, images were taken at the same condition.

\section{Preembedding immunoelectron microscopy}

All incubations were performed at room temperature and PBS containing $0.1 \%$ Tween20 was used as a dilution and washing buffer. Sections were incubated in 10\% normal goat serum (Nichirei, Tokyo, Japan) for $20 \mathrm{~min}$, and with primary antibody against GluK2/3 (1 $\mathrm{gg} / \mathrm{ml}$ ) overnight and then with secondary antibodies linked to 1.4-nm gold particles (1:100; Nanogold; Nanoprobes) for $4 \mathrm{~h}$. After extensive washing with PBST and HEPES buffer (200 mM sucrose, $50 \mathrm{mM}$ HEPES, pH 8.0), immunogold was intensified with a silver enhancement kit (R-GENT SEEM; Aurion) for 45-60 min. Sections were further treated with $1 \%$ osmium tetroxide for 15 min, stained with $2 \%$ uranyl acetate for $20 \mathrm{~min}$, dehydrated with graded ethanol series, and embedded in Epon 812 (TAAB). After polymerization at $60^{\circ} \mathrm{C}$ for $48 \mathrm{~h}$, ultrathin sections were prepared with an ultramicrotome (Ultracut; Leica), mounted on copper-mesh grids and stained with $2 \%$ uranyl acetate for $5 \mathrm{~min}$ and Reynold's lead citrate solution for $1 \mathrm{~min}$. Photographs were taken with a JEM1400 electron microscope (JEOL, Tokyo, Japan). Electron micrographs were randomly taken within $\sim 5 \mu \mathrm{m}$ from the surface to avoid false-negative areas. To quantify metal particle labeling, 3 $\times 3$ montage images $(\sim 6 \mu \mathrm{m} \times 6 \mu \mathrm{m})$ were randomly taken at a magnification of $15,000 \times$. 
1 For quantitative analysis, plasma membrane-attached immunogold particles, being defined as

2 those apart $<35 \mathrm{~nm}$ from the cell membrane, were counted and analyzed using MetaMorph

3 software (Molecular Devices). The mean number of membrane-attached gold particles per $1 \mu \mathrm{m}$

4 of the plasma membrane was counted for each neuronal compartment (dendritic spine, dendritic

5 shaft, and soma). Measurements were made from three WT and two GluK2 KO mice and pooled

6 together, because there was no significant difference in the labeling density in the same genotype.

7 In each neuronal compartment, labeling density was calculated for individual profile. Statistical

8 analyses were performed using GraphPad Prism 9.0 software (GraphPad Software). All data are

9 given as mean \pm SEM. Data were analyzed using Kruskal-Wallis test followed by Dunn's post

10 Test. ${ }^{*} p<0.05 ; * * p<0.01 ; * * * p<0.001$

\section{Results}

\section{Kainate receptors mediate inward currents and action potential firing in hilar mossy cells}

To test whether MCs expressed functional KARs, we first performed whole-cell patch clamp recordings from MCs in acute rat hippocampal slices and bath applied the KAR agonist KA. MCs were identified based on the high frequency of spontaneous EPSCs, non-burst firing pattern upon depolarization, and action potentials with almost no afterhyperpolarization (see Methods) (Larimer and Strowbridge, 2008) (Fig. 1A). To confirm the identity of the recorded cell, we loaded putative MCs with biocytin and stained with Alexa 594-conjugated streptavidin, and confirmed the presence of TEs, a hallmark of MCs (Fig. 1A) (Scharfman and Schwartzkroin, 1988). We examined whether KA bath application induced KAR-mediated inward currents in MCs, as previously shown in KAR-expressing CA3 pyramidal cells (Castillo et al., 1997; Mulle et al., 1998) To isolate these currents, recordings were performed in the presence of LY303070 (15 $\mu M)$, DAPV $(25 \mu \mathrm{M})$, picrotoxin $(50 \mu \mathrm{M})$ and CGP35348 $(3 \mu \mathrm{M})$ to block AMPARs, NMDARs, GABA $A_{A}$ and $\mathrm{GABA}_{B}$ receptors, respectively, and $\mathrm{MCs}$ were voltage clamped at $-60 \mathrm{mV}$. Under these recording conditions, KA bath application $(0.3 \mu \mathrm{M}$ and $3 \mu \mathrm{M})$ induced large, concentration-dependent inward currents in MCs (Fig. 1B,C) $(\Delta$ l holding MC: $0.3 \mu \mathrm{M} \mathrm{KA}: 165.3 \pm 28.56$ pA; $n=5 a / 5 c ; 3 \mu M ~ K A$ : $736.24 \pm 82.34 \mathrm{pA} ; \mathrm{n}=4 \mathrm{a} / 4 \mathrm{c}-$ one of the cells died after $0.3 \mu \mathrm{M}$ application). In contrast, the same concentrations of KA induced modest currents in GCs ( $\Delta$ l holding GC: $0.3 \mu \mathrm{MA}: 30.73 \pm$ $1.38 \mathrm{pA} ; \mathrm{n}=3 \mathrm{a} / 3 \mathrm{c} ; 3 \mu \mathrm{M}$ KA: $72.21 \pm 6.31 \mathrm{pA} ; \mathrm{n}=3 \mathrm{a} / 3 \mathrm{c})$. By activating KARs in CA3 pyramidal cells, KA application could recruit CA3 pyramidal cells (Robinson and Deadwyler, 1981; 
1 Westbrook and Lothman, 1983; Castillo et al., 1997) which make synaptic contacts with MCs

2 (Scharfman, 1994) and could indirectly activate KARs in MCs. To test this possibility, action

3 potential generation was prevented by perfusing the voltage-gated sodium channel blocker

4 tetrodotoxin (TTX, $0.5 \mu \mathrm{M})$ in the bath. In the presence of TTX, KA-induced currents were not

5 significantly different from control conditions (Fig. 1D,E) $(\Delta$ I holding MC + TTX, $0.3 \mu M$ KA : 117.3

$6 \pm p A ; n=5 a / 6 c ; 3 \mu M ~ K A: 765.19 \pm 79.06 p A ; n=5 a / 6 c ; 0.3 \mu M$ control vs TTX: $n . s . p=0.12045$,

7 two sample t Test; $3 \mu \mathrm{M}$ control vs TTX: $n . s . p=0.81287$ : two sample t Test), indicating that these

8 currents do not result from indirect activation of CA3 pyramidal neurons. In addition, the

9 competitive AMPAR/KAR antagonist NBQX $(25 \mu \mathrm{M})$ abolished KA-mediated inward currents,

10 strongly suggesting these currents were mediated by KAR activation in MCs (Fig. 1D,E) $(\Delta \mathrm{I}$

11 holding MC $0.3 \mu \mathrm{M}$ KA control: $182.78 \pm 25.7 \mathrm{pA} ; \mathrm{n}=3 \mathrm{a} / 4 \mathrm{c} ; 3 \mu \mathrm{M} \mathrm{KA}+25 \mu \mathrm{M}$ NBQX: $12.99 \pm$

$123.31 ; n=3 a / 4 c ; 0.3 \mu M$ KA vs $3 \mu \mathrm{M} \mathrm{KA}+\mathrm{NBQX}:{ }^{* * *} \mathrm{p}=0.000012$ : two sample t Test). Lastly, KA

13 bath application induced currents in MCs of mouse hippocampal slices,which were abolished in

14 GluK2 KO mice (Fig. 1F,G) ( $\Delta$ I holding MC WT; $0.1 \mu \mathrm{M}$ KA: $58.33 \pm 19.49$ pA, $0.3 \mu \mathrm{M} \mathrm{KA:} 75.44$

$15 \pm 13.87,1 \mu \mathrm{M}$ KA: $233.91 \pm 15.67$ pA, $3 \mu \mathrm{M} \mathrm{KA}: 494.32 \pm 85.01$ pA; $\Delta$ I holding GluK2 KO; $0.1 \mu \mathrm{M}$ KA: $19.77 \pm 9.27$ pA, $0.3 \mu \mathrm{M}$ KA: $13.35 \pm 4.44$ pA, $1 \mu \mathrm{M} \mathrm{KA}: 24.74 \pm 10.55$ pA, $3 \mu \mathrm{M} \mathrm{KA}: 14.39 \pm$ $5.04 \mathrm{pA}$; WT vs GluK2 KO: $F(1,3)=146.98864$, ${ }^{* *} \mathrm{p}=0.00121$; two-way ANOVA repeated measures), indicating that these currents are mediated by GluK2-containing KARs.

We hypothesized that KAR-mediated currents can produce enough depolarization to drive MC action potential firing. To test this possibility, we recorded MCs in current-clamp mode before and after KA application. Given that hippocampal interneurons impinging on MCs could express functional KARs (Frerking et al., 1998), these experiments were performed with intact excitatory and inhibitory components of synaptic transmission in order to assess the net effect of KAR activation on MC firing. Under these recording conditions, bath application of $0.3 \mu \mathrm{M}$ and $3.0 \mu \mathrm{M}$ $\mathrm{KA}$ induced strong MC firing (Fig. 2A) (WT average firing rate $0.3 \mu \mathrm{M} K A$ : $0.333 \mu \mathrm{M} \pm 0.025$ spikes/s; $n=2 a / 3 c ; 3 \mu \mathrm{MA}: 5.54 \pm 0.28 ; n=2 a / 3 c)$, and this effect was abolished in GluK2 KO mice (Fig. 2B). These results indicate that activation of GuK2-containing KARs with low concentrations of the agonist KA can powerfully drive MCs. 
1 We next sought to determine the subcellular localization of KARs on MCs. Because of the strong

2 structural and functional similarities between CA3 pyramidal cells and MCs, we tested whether

3 MF activation elicits KAR-EPSCs in MCs as previously shown at MF inputs onto CA3 pyramidal

4 cells (Castillo et al., 1997). To this end, we evoked AMPAR-EPSCs by stimulating MF axons with

5 two stimuli to boost glutamate release from MFs (5 ms inter-stimulus interval) in the presence of

6 a cocktail of NMDARs, $G_{A B A}$ and $G_{A B A}$ receptor antagonists (see Methods). We then

7 attempted to isolate the KAR-mediated component of the MF-EPSC by applying the selective,

8 non-competitive AMPAR antagonist GYKI $53655(30 \mu \mathrm{M})$. GYKI application abolished the

9 AMPAR-EPSCs but surprisingly, it failed to uncover a KAR-mediated EPSC (Fig. 3A) (EPSC

10 amplitude post GYKI application: $2.35 \pm 0.52 \%$ of baseline; $n=4 \mathrm{a} / 5 \mathrm{~s})$. In addition, increasing the

11 number of stimuli (from 2 to 5), a manipulation expected to increase the likelihood of detecting

12 KAR-EPSCs at the MF-CA3 synapse (Castillo et al., 1997), did not generate any detectable

13 current either (data not shown; 5 pulses: $2.108 \pm 0.415 \%$ of baseline; $n=4 a / 5 s$ ). To verify that

14 the EPSCs were MF-mediated, in a separate set of experiments, we applied the mGluR2/3

15 agonist DCG-IV $(1 \mu \mathrm{M})$ which selectively blocks glutamate release at MF-MC synapses (Fig. 3B)

16 (Lysetskiy et al., 2005; Hedrick et al., 2017). DCG-IV reduced synaptic responses by $\sim 70 \%$,

17 indicating our stimulation mainly recruited MF inputs onto MCs (EPSC amplitude post DCG IV:

$1829.35 \pm 7.07 \%$ of baseline; $n=3 a / 4 s$ ). As a positive control, and as previously reported (Castillo

19 et al., 1997), MF stimulation elicited GYKI-resistant, NBQX-sensitive KAR-EPSCs in CA3

20 pyramidal neurons (Fig. 3C) (EPSC amplitude post GYKI application: $15.85 \pm 6.59 \%$ of baseline;

$21 \mathrm{n}=2 \mathrm{a} / 4 \mathrm{~s} ;$ KAR-EPSC amplitude post NBQX application: $0.47 \pm 0.25 \%$ of baseline; $\mathrm{n}=2 \mathrm{a} / 4 \mathrm{~s}$ ).

22 These results indicate that in contrast to MF-CA3 synapses, KARs do not mediate synaptic

23 transmission at MF-MC synapses. Given the robust activation of MCs by low concentrations of

24 KA (Figs. 1,2), our findings thus far suggest KARs in MCs are extrasynaptic.

\section{Distinct subcellular localization of KARs in CA3 pyramidal cells and mossy cells}

To determine the anatomical localization of KARs in MCs, we applied immunostaining to tissue sections fixed with a glyoxal-based fixative (see Methods), which is effective for detection of both non-synaptic and synaptic molecules. First, we confirmed the specificity of the antibody against GluK2/3 by blank labeling in GluK2 KO hippocampus (Fig. 4A,B). In WT mice, the antibody yielded a contrasting pattern of labeling across hippocampal subregions: intense and coarse punctate labeling in the CA3 stratum lucidum, and moderate and diffuse labeling in the hilus (Fig 
1 allowed us to distinguish excitatory MCs from inhibitory calretinin-positive interneurons, and to

2 examine if MCs express GluK2/3 (Fig. 4C,D) together with or without the excitatory postsynaptic

3 marker PSD95 (Fig. 4C), or the KAR auxiliary subunit Neto1 (Fig. 4D). In CA3 stratum lucidum,

4 GluK2/3-positive puncta were intense and aggregated into large clusters and were almost 5 perfectly overlapped with PSD95 (Fig. 4E,F), suggesting exclusive localization in MF-CA3 6 pyramidal cell synapse. Compared with CA3, GluK2/3 labeling was smaller and less frequent in 7 the hilus of the DG (Fig. 4G,H). MC soma and dendrites, which can be unequivocally identified 8 as calretinin-positive and GFP-negative structures (Fig. 4G), were associated with GluK2/3 9 puncta that did not colocalize with PSD95 (Fig. 4H). Similarly, while Neto1 staining was overlapped with GluK2/3-positive puncta in stratum lucidum (Fig. 4I,J), it was not found around

11 MC soma and dendrites (Fig. 4K,L). Together, these findings suggest that GluK2/3-containing

12 KARs in MCs are expressed at extrasynaptic sites.

For a more accurate assessment of the subcellular localization of KARs in MCs, we performed pre-embedding immunoelectron microscopy for GluK2/3. In WT mice, metal particles for GluK2/3 were observed on the postsynaptic membrane of TEs (Fig. 5A,G, blue) of CA3 pyramidal cells facing large MF boutons (12.1 \pm 0.95 particles/mm). In GluK2 KO mice, immunolabeling was essentially absent on the postsynaptic membrane of CA3 spines (Fig. 5B,G blue), confirming the specificity of the immunolabeling $(0.07 \pm 0.07$ particles $/ \mathrm{mm}$; Dunn's multiple comparison test; $p<$ 0.0001, compared to WT). In the DG hilus, MCs can be identified as having spiny dendrites contacted with large MF terminals (Acsady et al., 1998). In contrast to MF-CA3 synapses, MFMC synapses were not labeled for GluK2/3 (Fig. 5C,G) $(0.06 \pm 0.04$ particles/ $\mu \mathrm{m}$ in WT, vs 0.01 \pm 0.01 particles/ $\mu \mathrm{m}$ in GluK2 KO; $p>0.99$ ). Instead, occasional weak labeling was observed on the non-synaptic membrane of dendritic shaft and spines of MCs (Fig. 5E,F green). The density of non-synaptic particles was much lower than that at MF-CA3 synapses ( $p=0.0137$ ), but significantly higher than their counterparts in GluK2 KO (Fig. 5D,G; $4.1 \pm 0.8$ particles/ $/$ m in WT vs $0.02 \pm 0.01$ particles/ $\mu \mathrm{m}$ in GluK2 KO; $p=0.008$ ). These results not only demonstrate the presence of KARs in MCs but also show that, in contrast to CA3 pyramidal neurons, GluK2containing KARs are exclusively expressed at non-synaptic sites in proximity of MF-MC synapses.

\section{Activation of KARs in mossy cells by increase in ambient glutamate.}

Given the extracellular location of KARs in MCs we hypothesized that these receptors are activated by ambient glutamate. To test this possibility, we blocked excitatory amino acid 
1 transporters (EAATs), a manipulation that can raise extracellular glutamate and activate

2 extrasynaptic NMDARs (Le Meur et al., 2007). We first examined the effect of the non-selective

3 EAAT blocker DL-TBOA $(100 \mu \mathrm{M})$ on MC holding current in presence of antagonists of AMPARs,

4 NMDAR, GABA $A$ and $G_{B B A}$ receptors (see Methods). Bath application of TBOA mediated a

5 significant NBQX-sensitive inward current in MCs, suggesting that KARs could be activated by

6 endogenous glutamate (Fig 6A-C) $\left(\Delta\right.$ I holding MC + TBOA: $61.24 \pm 18.61 p A ;{ }^{*} p=0.02173$ one

7 sample $\mathrm{t}$ Test). We next used the more selective blocker dihydrokainic acid (DHK), which

8 selectively blocks EAAT2 (GLT-1), a glutamate transporter that accounts for $\sim 90 \%$ of glutamate

9 uptake (Rose et al., 2017) and is enriched in the telencephalon including the hippocampus

10 (Chaudhry et al., 1995). Bath application of $100 \mu \mathrm{M}$ DHK also induced NBQX-sensitive inward

11 currents in MCs (Fig. 6A-C), strongly suggesting that DHK-induced currents are mediated by

12 activation of KARs ( $\Delta$ I holding MC + DHK: $28.06 \pm 7.4 p A ; n=3 a / 6 c ; n=4 a / 6 c)$. To determine

13 that DHK-induced currents was due to activation of KARs, we repeated the experiment in G/uK2

$14 \mathrm{KO}$ mice, and found that in these mice DHK failed to induce inward currents in MCs (Fig. 6A,C)

$15(\Delta$ l holding MC + DHK GluK2 KO: $-8.5 \pm 7.47 ; n=3 a / 4 c$; DHK vs DHK GluK2 KO mice: * $p=$ 160.0105 two sample $t$ Test). These finding suggest that increases in ambient glutamate can 17 activate extrasynaptic MC-KARs.

DISCUSSION

In this study, we provide functional and anatomical evidence that MCs express extrasynaptic KARs whose activation in the rodent hippocampus can drive MCs. Specifically, we show that low concentrations of KA induced inward currents and action potential firing of MCs. In contrast, KAinduced currents were nearly absent in GCs, indicating that KARs have a unique pattern of expression among excitatory cells in the DG. Unexpectedly, MF activation failed to evoke a KAREPSCs in MCs, indicating that MF-MC synapses, unlike MF-CA3 synapses, do not normally express synaptic KARs. Our immunofluorescence and immunoelectron microscopy data confirmed that KARs in MCs are sparsely distributed at extrasynaptic sites and mainly excluded from postsynaptic compartments. Finally, blockade of the astrocytic glutamate transporter EAAT2 revealed that MC-KARs can be activated by increasing ambient glutamate. 
1 The presence of extrasynaptic KARs has previously been suggested in hippocampal CA1 2 pyramidal neurons (Bureau et al., 1999), striatal medium spiny neurons (Chergui et al., 2000) and

3 cortical layer $V$ pyramidal neurons (Eder et al., 2003). These functional studies inferred the 4 presence of extrasynaptic KARs given the robust effects to bath applied KAR agonist (e.g., 5 membrane depolarization, inward current, action potential firing) with little evidence for KAR6 mediated EPSCs. Of note, none of these studies provided ultrastructural evidence in support of 7 extrasynaptic KARs. To the best of our knowledge, our immunoelectron microscopy data together 8 with our electrophysiological characterization is the first direct evidence of a selective 9 extrasynaptic localization of functional KARs in the mammalian brain.

Given the similarities between MF-CA3 and MF-MC synapses, the absence of KARs at MF-MC synapses is intriguing. Based on the presence of a GYKI-resistant component following MF stimulation, a previous study reported the presence of postsynaptic KARs in MCs (Hedrick et al., 2017). However, these currents were not validated in GluK2 KO mice and showed relatively fast kinetics, which is unusual for KAR-EPSCs. Our study does not discard the possibility that KARs could be expressed at MF-MC synapses early during development (Lauri and Taira, 2011; Lerma and Marques, 2013). The molecular mechanisms that target KARs to the synapse remain unclear, but several KAR interacting proteins such as Neto 1 and 2 (Straub et al., 2011; Tomita and Castillo, 2012; Wyeth et al., 2014), N-cadherins (Coussen et al., 2002; Fievre et al., 2016) and presynaptic C1ql family proteins (Matsuda et al., 2016; Straub et al., 2016) may contribute. Consistent with data derived from a population-level transcriptomics study in the hippocampus (Cembrowski et al., 2016), we found that Neto1 signal was absent from MCs (Fig. 4), suggesting that lack of Neto1 could contribute to the low expression of KARs at the synapse (Wyeth et al., 2014). However, lack of GluK2-containing KARs also leads to reduced levels of Neto1 (Straub et al., 2011). The C-terminal domain of KARs themselves is important for the synaptic stabilization of KARs in the cerebellum (Straub et al., 2016). Additionally, phosphorylation of specific residues in the C-terminal and other intracellular regions of KARs has been implicated in the modulation of KARs function and trafficking (Wang et al., 1993; Kornreich et al., 2007; Carta et al., 2013; Zhu et al., 2014). Further studies are required to clarify the molecular mechanisms that determine the exclusion of KARs from MF-MC synapses. 
1 Like other extrasynaptic receptors, KARs in MCs could be engaged by a rise in ambient

2 glutamate, which can occur as a result of glutamate spillover during sustained synaptic activity

3 (Le Meur et al., 2007; Rose et al., 2017). Glutamate could also arise from MC dendrites, as

4 previously reported in neocortical and cerebellar neurons (Zilberter, 2000; Shin et al., 2008), and

5 activate extrasynaptic KARs. We found that blockade of EAAT2 induces KAR-mediated inward

6 currents likely due to the increase in extracellular glutamate. In the CA1 area of the hippocampus,

7 activation of extrasynaptic receptors by synaptically released glutamate is limited by efficient

8 astrocytic EAAT2 activity (Diamond and Jahr, 2000), consistent with a neuroprotective role of this

9 transporter (Kong et al., 2012; Pajarillo et al., 2019). However, EAAT2 may saturate in other brain

10 areas (Armbruster et al., 2016; Pinky et al., 2018). EAAT2 saturation during neuronal hyperactivity

11 could enable the activation of extrasynaptic KARs at MCs. Alternatively, extrasynaptic KARs could

12 be activated by glutamate released from astrocytes (Araque et al., 2014; Pal, 2015), as previously

13 reported in CA1 GABAergic interneurons (Liu et al., 2004). There is evidence that glutamate released from astrocytes can also activate extrasynaptic NMDARs in CA1 pyramidal neurons (Fellin et al., 2004), and depolarize both hilar GABAergic interneurons and MCs (Pabst et al., 2016). These depolarizations were blocked by non-selective antagonism of all ionotropic glutamate receptors, raising the possibility that extrasynaptic KARs could be implicated. Future work is required to determine whether astrocytic processes (Gavrilov et al., 2018) could release glutamate in proximity to extrasynaptic KARs, thereby avoiding glutamate uptake by EAAT2.

Although the precise role for extrasynaptic KARs in MCs is unclear, they might detect changes in the levels of ambient glutamate and mediate tonic depolarization. In vivo, MCs display high level of activity compared to neighboring GCs (Danielson et al., 2017; GoodSmith et al., 2017; Senzai and Buzsaki, 2017). In standard home cage rats, MCs stain positive for the activity-dependent immediately early gene cFos (Duffy et al., 2013), suggesting that even at the basal level, MCs are remarkably active. It is possible that in behaving animals, where spontaneous activity is most likely higher than in vitro, glutamate might escape reuptake by EAATs and activate extrasynaptic KARs. During periods of particularly high activity and potential EAAT2 saturation, KARs might act as nonlinear integrators of synaptic inputs, and enhance MC output. KARs can also work in a metabotropic fashion and could potentially affect MCs excitability by suppressing the slow afterhyperpolarization (Melyan et al., 2002; Ruiz et al., 2005).Ultimately, MC-KARs could contribute to the promiscuous activity of MCs in multiple locations and environments (Danielson et al., 2017; GoodSmith et al., 2017; Senzai and Buzsaki, 2017). 
2 Both MCs and KARs have been linked to several neurological and psychiatric disorders (Ratzliff 3 et al., 2002; Lerma and Marques, 2013; Scharfman, 2016). Of particular relevance is the strong 4 link between KARs and MCs with TLE. KARs have been strongly implicated in epilepsy (Crepel 5 and Mulle, 2015; Falcon-Moya et al., 2018), and KA-induced TLE is one of the most widely used 6 models of TLE (Levesque and Avoli, 2013; Rusina et al., 2021). The importance of KARs in KA7 induced TLE is highlighted by the fact that loss of GluK2-containing KARs, strongly reduces the susceptibility to KA-induced seizures (Mulle et al., 1998). Similarly, MCs have been proposed to have a proepileptogenic role in the early phases of TLE (Ratzliff et al., 2002; Botterill et al., 2019) and to undergo prominent cell-death in both animal models of epilepsy (Blumcke et al., 2000) and in human patients (Margerison and Corsellis, 1966; Seress et al., 2009). However, the precise mechanism through which KARs and MCs are involved in TLE is still unclear. Expression of KARs in MCs strongly suggests that MCs could be a direct target of KA in KA-induced TLE. KA-induced MCs firing could contribute to hyperexcitability of the associative GC-MC-GC network and to the generation of seizures. Moreover, sustained KAR-mediated MCs firing could be a critical trigger for long-lasting forms of plasticity in the DG associative network (Hashimotodani et al., 2017), which could contribute to the prolongation of epileptic activity. A major limitation for the study of MC function in behavior is the lack of molecular tools that target MCs specifically. Thus far, manipulation of MCs activity in vivo relied on viral delivery of constructs under the control of promoters that are not highly specific for MCs (Jinde et al., 2012; Puighermanal et al., 2015). Establishing the precise role of MC-KARs on hippocampal function and TLE will require novel

22 strategies such as intersectional genetics approaches (Dymecki et al., 2010; Graybuck et al., 23 2021) that will allow more selective targeting of MCs while sparing neighboring KAR-expressing 24 cells such as CA3 pyramidal neurons and hilar interneurons. 


\section{References}

Acsady L, Kamondi A, Sik A, Freund T, Buzsaki G (1998) GABAergic cells are the major postsynaptic targets of mossy fibers in the rat hippocampus. J Neurosci 18:3386-3403.

Amaral DG, Dent JA (1981) Development of the mossy fibers of the dentate gyrus: I. A light and electron microscopic study of the mossy fibers and their expansions. J Comp Neurol 195:51-86.

Araque A, Carmignoto G, Haydon PG, Oliet SH, Robitaille R, Volterra A (2014) Gliotransmitters travel in time and space. Neuron 81:728-739.

Armbruster M, Hanson E, Dulla CG (2016) Glutamate Clearance Is Locally Modulated by Presynaptic Neuronal Activity in the Cerebral Cortex. J Neurosci 36:10404-10415.

Blumcke I, Suter B, Behle K, Kuhn R, Schramm J, Elger CE, Wiestler OD (2000) Loss of hilar mossy cells in Ammon's horn sclerosis. Epilepsia 41 Suppl 6:S174-180.

Botterill JJ, Lu YL, LaFrancois JJ, Bernstein HL, Alcantara-Gonzalez D, Jain S, Leary P, Scharfman HE (2019) An Excitatory and Epileptogenic Effect of Dentate Gyrus Mossy Cells in a Mouse Model of Epilepsy. Cell Rep 29:2875-2889 e2876.

Buckmaster PS, Schwartzkroin PA (1994) Hippocampal mossy cell function: a speculative view. Hippocampus 4:393-402.

Buckmaster PS, Jongen-Relo AL (1999) Highly specific neuron loss preserves lateral inhibitory circuits in the dentate gyrus of kainate-induced epileptic rats. J Neurosci 19:9519-9529.

Buckmaster PS, Wenzel HJ, Kunkel DD, Schwartzkroin PA (1996) Axon arbors and synaptic connections of hippocampal mossy cells in the rat in vivo. J Comp Neurol 366:271-292.

Bureau I, Bischoff S, Heinemann SF, Mulle C (1999) Kainate receptor-mediated responses in the CA1 field of wild-type and GluR6-deficient mice. J Neurosci 19:653-663.

Carta M, Opazo P, Veran J, Athane A, Choquet D, Coussen F, Mulle C (2013) CaMKII-dependent phosphorylation of GluK5 mediates plasticity of kainate receptors. EMBO J 32:496-510.

Castillo PE, Malenka RC, Nicoll RA (1997) Kainate receptors mediate a slow postsynaptic current in hippocampal CA3 neurons. Nature 388:182-186.

Cembrowski MS, Wang L, Sugino K, Shields BC, Spruston N (2016) Hipposeq: a comprehensive RNA-seq database of gene expression in hippocampal principal neurons. Elife 5:e14997.

Chaudhry FA, Lehre KP, van Lookeren Campagne M, Ottersen OP, Danbolt NC, Storm-Mathisen J (1995) Glutamate transporters in glial plasma membranes: highly differentiated localizations revealed by quantitative ultrastructural immunocytochemistry. Neuron 15:711-720.

Chergui K, Bouron A, Normand E, Mulle C (2000) Functional GluR6 kainate receptors in the striatum: indirect downregulation of synaptic transmission. J Neurosci 20:2175-2182.

Coussen F, Normand E, Marchal C, Costet P, Choquet D, Lambert M, Mege RM, Mulle C (2002) Recruitment of the kainate receptor subunit glutamate receptor 6 by cadherin/catenin complexes. J Neurosci 22:6426-6436.

Crepel V, Mulle C (2015) Physiopathology of kainate receptors in epilepsy. Curr Opin Pharmacol 20:83-88.

Danielson NB, Turi GF, Ladow M, Chavlis S, Petrantonakis PC, Poirazi P, Losonczy A (2017) In Vivo Imaging of Dentate Gyrus Mossy Cells in Behaving Mice. Neuron 93:552-559 e554.

Diamond JS, Jahr CE (2000) Synaptically released glutamate does not overwhelm transporters on hippocampal astrocytes during high-frequency stimulation. J Neurophysiol 83:2835-2843.

Duffy AM, Schaner MJ, Chin J, Scharfman HE (2013) Expression of c-fos in hilar mossy cells of the dentate gyrus in vivo. Hippocampus 23:649-655.

Dymecki SM, Ray RS, Kim JC (2010) Mapping cell fate and function using recombinase-based intersectional strategies. Methods Enzymol 477:183-213. 
Eder M, Becker K, Rammes G, Schierloh A, Azad SC, Zieglgansberger W, Dodt HU (2003) Distribution and properties of functional postsynaptic kainate receptors on neocortical layer $\mathrm{V}$ pyramidal neurons. J Neurosci 23:6660-6670.

Falcon-Moya R, Sihra TS, Rodriguez-Moreno A (2018) Kainate Receptors: Role in Epilepsy. Front Mol Neurosci 11:217.

Fellin T, Pascual O, Gobbo S, Pozzan T, Haydon PG, Carmignoto G (2004) Neuronal synchrony mediated by astrocytic glutamate through activation of extrasynaptic NMDA receptors. Neuron 43:729-743.

Fievre S, Carta M, Chamma I, Labrousse V, Thoumine O, Mulle C (2016) Molecular determinants for the strictly compartmentalized expression of kainate receptors in CA3 pyramidal cells. Nat Commun 7:12738.

Fredes F, Silva MA, Koppensteiner P, Kobayashi K, Joesch M, Shigemoto R (2021) Ventro-dorsal Hippocampal Pathway Gates Novelty-Induced Contextual Memory Formation. Curr Biol 31:25-38 e25.

Frerking M, Malenka RC, Nicoll RA (1998) Synaptic activation of kainate receptors on hippocampal interneurons. Nat Neurosci 1:479-486.

Frotscher M, Seress L, Schwerdtfeger WK, Buhl E (1991) The mossy cells of the fascia dentata: a comparative study of their fine structure and synaptic connections in rodents and primates. J Comp Neurol 312:145-163.

Fukaya M, Watanabe M (2000) Improved immunohistochemical detection of postsynaptically located PSD-95/SAP90 protein family by protease section pretreatment: a study in the adult mouse brain. J Comp Neurol 426:572-586.

Gavrilov N, Golyagina I, Brazhe A, Scimemi A, Turlapov V, Semyanov A (2018) Astrocytic Coverage of Dendritic Spines, Dendritic Shafts, and Axonal Boutons in Hippocampal Neuropil. Front Cell Neurosci 12:248.

GoodSmith D, Chen X, Wang C, Kim SH, Song H, Burgalossi A, Christian KM, Knierim JJ (2017) Spatial Representations of Granule Cells and Mossy Cells of the Dentate Gyrus. Neuron 93:677-690 e675.

Graybuck LT et al. (2021) Enhancer viruses for combinatorial cell-subclass-specific labeling. Neuron.

Hashimotodani Y, Nasrallah K, Jensen KR, Chavez AE, Carrera D, Castillo PE (2017) LTP at Hilar Mossy CellDentate Granule Cell Synapses Modulates Dentate Gyrus Output by Increasing Excitation/Inhibition Balance. Neuron 95:928-943 e923.

Hedrick TP, Nobis WP, Foote KM, Ishii T, Chetkovich DM, Swanson GT (2017) Excitatory Synaptic Input to Hilar Mossy Cells under Basal and Hyperexcitable Conditions. eNeuro 4.

Henze DA, Wittner L, Buzsaki G (2002) Single granule cells reliably discharge targets in the hippocampal CA3 network in vivo. Nat Neurosci 5:790-795.

Jinde S, Zsiros V, Jiang Z, Nakao K, Pickel J, Kohno K, Belforte JE, Nakazawa K (2012) Hilar mossy cell degeneration causes transient dentate granule cell hyperexcitability and impaired pattern separation. Neuron 76:1189-1200.

Kamiya H, Shinozaki H, Yamamoto C (1996) Activation of metabotropic glutamate receptor type 2/3 suppresses transmission at rat hippocampal mossy fibre synapses. J Physiol 493 ( Pt 2):447-455.

Kong Q, Takahashi K, Schulte D, Stouffer N, Lin Y, Lin CL (2012) Increased glial glutamate transporter EAAT2 expression reduces epileptogenic processes following pilocarpine-induced status epilepticus. Neurobiol Dis 47:145-154.

Kornreich BG, Niu L, Roberson MS, Oswald RE (2007) Identification of C-terminal domain residues involved in protein kinase A-mediated potentiation of kainate receptor subtype 6 . Neuroscience 146:11581168.

Larimer P, Strowbridge BW (2008) Nonrandom local circuits in the dentate gyrus. J Neurosci 28:1221212223. 
Lauri SE, Taira T (2011) Role of kainate receptors in network activity during development. Adv Exp Med Biol 717:81-91.

Le Meur K, Galante M, Angulo MC, Audinat E (2007) Tonic activation of NMDA receptors by ambient glutamate of non-synaptic origin in the rat hippocampus. J Physiol 580:373-383.

Lerma J, Marques JM (2013) Kainate receptors in health and disease. Neuron 80:292-311.

Levesque M, Avoli M (2013) The kainic acid model of temporal lobe epilepsy. Neurosci Biobehav Rev 37:2887-2899.

Liu QS, Xu Q, Arcuino G, Kang J, Nedergaard M (2004) Astrocyte-mediated activation of neuronal kainate receptors. Proc Natl Acad Sci U S A 101:3172-3177.

Lysetskiy M, Foldy C, Soltesz I (2005) Long- and short-term plasticity at mossy fiber synapses on mossy cells in the rat dentate gyrus. Hippocampus 15:691-696.

Margerison JH, Corsellis JA (1966) Epilepsy and the temporal lobes. A clinical, electroencephalographic and neuropathological study of the brain in epilepsy, with particular reference to the temporal lobes. Brain 89:499-530.

Matsuda K, Budisantoso T, Mitakidis N, Sugaya $Y$, Miura E, Kakegawa W, Yamasaki M, Konno K, Uchigashima M, Abe M, Watanabe I, Kano M, Watanabe M, Sakimura K, Aricescu AR, Yuzaki M (2016) Transsynaptic Modulation of Kainate Receptor Functions by C1q-like Proteins. Neuron 90:752-767.

Melyan Z, Wheal HV, Lancaster B (2002) Metabotropic-mediated kainate receptor regulation of IsAHP and excitability in pyramidal cells. Neuron 34:107-114.

Mulle C, Sailer A, Perez-Otano I, Dickinson-Anson H, Castillo PE, Bureau I, Maron C, Gage FH, Mann JR, Bettler B, Heinemann SF (1998) Altered synaptic physiology and reduced susceptibility to kainateinduced seizures in GluR6-deficient mice. Nature 392:601-605.

Nicoll RA, Schmitz D (2005) Synaptic plasticity at hippocampal mossy fibre synapses. Nat Rev Neurosci 6:863-876.

Pabst M, Braganza O, Dannenberg H, Hu W, Pothmann L, Rosen J, Mody I, van Loo K, Deisseroth K, Becker AJ, Schoch S, Beck H (2016) Astrocyte Intermediaries of Septal Cholinergic Modulation in the Hippocampus. Neuron 90:853-865.

Pajarillo E, Rizor A, Lee J, Aschner M, Lee E (2019) The role of astrocytic glutamate transporters GLT-1 and GLAST in neurological disorders: Potential targets for neurotherapeutics. Neuropharmacology 161:107559.

Pal B (2015) Astrocytic Actions on Extrasynaptic Neuronal Currents. Front Cell Neurosci 9:474.

Patton PE, McNaughton B (1995) Connection matrix of the hippocampal formation: I. The dentate gyrus. Hippocampus 5:245-286.

Pinky NF, Wilkie CM, Barnes JR, Parsons MP (2018) Region- and Activity-Dependent Regulation of Extracellular Glutamate. J Neurosci 38:5351-5366.

Puighermanal E, Biever A, Espallergues J, Gangarossa G, De Bundel D, Valjent E (2015) drd2-cre:ribotag mouse line unravels the possible diversity of dopamine $\mathrm{d} 2$ receptor-expressing cells of the dorsal mouse hippocampus. Hippocampus 25:858-875.

Ratzliff A, Santhakumar V, Howard A, Soltesz I (2002) Mossy cells in epilepsy: rigor mortis or vigor mortis? Trends Neurosci 25:140-144.

Ribak CE, Shapiro LA (2007) Ultrastructure and synaptic connectivity of cell types in the adult rat dentate gyrus. Prog Brain Res 163:155-166.

Ribak CE, Seress L, Amaral DG (1985) The development, ultrastructure and synaptic connections of the mossy cells of the dentate gyrus. J Neurocytol 14:835-857.

Richter KN et al. (2018) Glyoxal as an alternative fixative to formaldehyde in immunostaining and superresolution microscopy. EMBO J 37:139-159. 
Robinson JH, Deadwyler SA (1981) Kainic acid produces depolarization of CA3 pyramidal cells in the vitro hippocampal slice. Brain Res 221:117-127.

Rose CR, Felix L, Zeug A, Dietrich D, Reiner A, Henneberger C (2017) Astroglial Glutamate Signaling and Uptake in the Hippocampus. Front Mol Neurosci 10:451.

Ruiz A, Sachidhanandam S, Utvik JK, Coussen F, Mulle C (2005) Distinct subunits in heteromeric kainate receptors mediate ionotropic and metabotropic function at hippocampal mossy fiber synapses. J Neurosci 25:11710-11718.

Rusina E, Bernard C, Williamson A (2021) The Kainic Acid Models of Temporal Lobe Epilepsy. eNeuro 8.

Scharfman HE (1994) Evidence from simultaneous intracellular recordings in rat hippocampal slices that area CA3 pyramidal cells innervate dentate hilar mossy cells. J Neurophysiol 72:2167-2180.

Scharfman HE (2016) The enigmatic mossy cell of the dentate gyrus. Nat Rev Neurosci 17:562-575.

Scharfman HE (2018) Advances in understanding hilar mossy cells of the dentate gyrus. Cell Tissue Res 373:643-652.

Scharfman HE, Schwartzkroin PA (1988) Electrophysiology of morphologically identified mossy cells of the dentate hilus recorded in guinea pig hippocampal slices. J Neurosci 8:3812-3821.

Senzai Y, Buzsaki G (2017) Physiological Properties and Behavioral Correlates of Hippocampal Granule Cells and Mossy Cells. Neuron 93:691-704 e695.

Seress L, Abraham H, Horvath Z, Doczi T, Janszky J, Klemm J, Byrne R, Bakay RA (2009) Survival of mossy cells of the hippocampal dentate gyrus in humans with mesial temporal lobe epilepsy. J Neurosurg 111:1237-1247.

Shin JH, Kim YS, Linden DJ (2008) Dendritic glutamate release produces autocrine activation of mGluR1 in cerebellar Purkinje cells. Proc Natl Acad Sci U S A 105:746-750.

Sloviter RS, Zappone CA, Harvey BD, Bumanglag AV, Bender RA, Frotscher M (2003) "Dormant basket cell" hypothesis revisited: relative vulnerabilities of dentate gyrus mossy cells and inhibitory interneurons after hippocampal status epilepticus in the rat. J Comp Neurol 459:44-76.

Straub C, Hunt DL, Yamasaki M, Kim KS, Watanabe M, Castillo PE, Tomita S (2011) Distinct functions of kainate receptors in the brain are determined by the auxiliary subunit Neto1. Nat Neurosci 14:866-873.

Straub C, Noam Y, Nomura T, Yamasaki M, Yan D, Fernandes HB, Zhang P, Howe JR, Watanabe M, Contractor A, Tomita S (2016) Distinct Subunit Domains Govern Synaptic Stability and Specificity of the Kainate Receptor. Cell Rep 16:531-544.

Takasaki C, Yamasaki M, Uchigashima M, Konno K, Yanagawa Y, Watanabe M (2010) Cytochemical and cytological properties of perineuronal oligodendrocytes in the mouse cortex. Eur J Neurosci 32:1326-1336.

Tamamaki N, Yanagawa Y, Tomioka R, Miyazaki J, Obata K, Kaneko T (2003) Green fluorescent protein expression and colocalization with calretinin, parvalbumin, and somatostatin in the GAD67-GFP knock-in mouse. J Comp Neurol 467:60-79.

Tomita S, Castillo PE (2012) Neto1 and Neto2: auxiliary subunits that determine key properties of native kainate receptors. J Physiol 590:2217-2223.

Wang LY, Taverna FA, Huang XP, MacDonald JF, Hampson DR (1993) Phosphorylation and modulation of a kainate receptor (GluR6) by cAMP-dependent protein kinase. Science 259:1173-1175.

Wenzel HJ, Buckmaster PS, Anderson NL, Wenzel ME, Schwartzkroin PA (1997) Ultrastructural localization of neurotransmitter immunoreactivity in mossy cell axons and their synaptic targets in the rat dentate gyrus. Hippocampus 7:559-570.

Westbrook GL, Lothman EW (1983) Cellular and synaptic basis of kainic acid-induced hippocampal epileptiform activity. Brain Res 273:97-109. 
1 Wyeth MS, Pelkey KA, Petralia RS, Salter MW, Mclnnes RR, McBain CJ (2014) Neto auxiliary protein 2 interactions regulate kainate and NMDA receptor subunit localization at mossy fiber-CA3 3 pyramidal cell synapses. J Neurosci 34:622-628.

4 Zhu QJ, Kong FS, Xu H, Wang Y, Du CP, Sun CC, Liu Y, Li T, Hou XY (2014) Tyrosine phosphorylation of GluK2

5 up-regulates kainate receptor-mediated responses and downstream signaling after brain $6 \quad$ ischemia. Proc Natl Acad Sci U S A 111:13990-13995.

7 Zilberter Y (2000) Dendritic release of glutamate suppresses synaptic inhibition of pyramidal neurons in $8 \quad$ rat neocortex. J Physiol 528:489-496. 
Figure 1. Activation of KARs mediates inward currents in hilar mossy cells. (A) Identification of hilar mossy cells (MCs) in acute hippocampal slices. Left, schematic of MC recordings in the hilus of the dentate gyrus (DG). Middle, patched neurons were depolarized to analyze their firing properties. Right, post-hoc staining of a MC using Alexa 594-conjugated streptavidin. The yellow boxed area is magnified on the right-hand side. Patched cells were confirmed to be MCs if evoked spikes displayed no evident afterhyperpolarization and by the presence of thorny excrescences (TEs) (white arrowheads). (B) Representative experiment showing that bath application of 0.3 and $3 \mu \mathrm{M}$ kainic acid (KA) in the same cell induced concentration-dependent inward currents in MCs (top), but only a negligible inward current in dentate gyrus granule cells (GC) (bottom). (C) Summary plot of the amplitude of the inward currents ( $\Delta \mathrm{l}$ holding) induced by KA application. (D) Representative experiments showing that KA-induced inward current was not affected by coapplication of TTX $(0.5 \mu \mathrm{M})$ (top) but it was abolished by the AMPAR/KARs antagonist NBQX (25 $\mu \mathrm{M})($ bottom). A low concentration of $\mathrm{KA}(0.3 \mu \mathrm{M})$ was previously tested to verify the presence of a normal, fully reversible KA-induced current in the same cell. (E) Summary plot. (F) KA-induced currents in MCs were robust in WT (top) but abolished in GluK2 KO mice (bottom). (G) Concentration-response curve in WT and GluK2 KO mice. Data are presented as mean \pm S.E.M. MCs. (A) Top, Effect of of KA bath application $(0.3$ and $3 \mu \mathrm{M})$ on MCs membrane potential in current-clamp configuration. $3 \mu \mathrm{M}$ KA application induced firing with faster onset and higher frequency than $0.3 \mu \mathrm{M} \mathrm{KA}$. Firing in $3 \mu \mathrm{M} \mathrm{KA}$ eventually disappeared likely due to excessive depolarization and action potential refractoriness. Bottom, average firing rate histogram (expressed as spikes per second) for the experiments in top panel. Black and grey traces represent mean and S.E.M. of MCs firing rate. (B) Representative traces showing no effect of KA application on MCs firing in GluK2 KO mice.

Figure 3. KAR-mediated transmission at MF-CA3 but not MF-MC synapses. (A). Left, Bath application of the selective AMPAR antagonist GYKI $53655(30 \mu \mathrm{M})$ abolished synaptic transmission at MF-MC synapses. Right, representative average traces (30 consecutive responses). (B) Bath application of the mGluR2/3 agonist DCG-IV $(1 \mu \mathrm{M})$ significantly reduced MF-MC EPSCs ( 70\%). (C) Left, GYKI 53655 application (30 $\mu \mathrm{M})$ blocked AMPAR-mediated transmission at the MF-CA3 synapse, thus revealing a KAR-mediated component that was blocked by $25 \mu \mathrm{M}$ NBQX. Middle, representative average traces (30 consecutive responses) before and after GYKI application, and after subsequent application of NBQX. Right, normalized 
1 included in this figure, stimulus artifacts were deleted for clarity. Data are presented as mean \pm

2 S.E.M.

3

Figure 4. Contrasting localization of GluK2/3 and its molecular partners in CA3 stratum Iucidum and DG hilus. (A,B) In WT mice, GluK2/3 labeling is intense in CA3 stratum lucidum, while it is moderate and diffuse in the dentate gyrus (A). Note the lack of GluK2/3 staining in GluK2 KO mice, indicating the specificity of the GluK2/3 antibody and exclusive expression of GluK2 in these hippocampal regions (B). (C) Quadplex immunofluorescence for GFP $\left(C_{1}\right.$, white), calretinin $\left(\mathrm{C}_{2}\right.$, blue), GluK2/3 $\left(\mathrm{C}_{4}\right.$, red), and PSD95 $\left(\mathrm{C}_{5}\right.$, green $)$ in GAD67 $7^{+/ G F P}$ mice. (D) Double immunofluorescence for GluK2/3 ( $D_{1}$, red) and Neto1 $\left(D_{2}\right.$, green). Note that intense signal for Neto 1 is almost limited to CA3 stratum lucidum. (E-H) Distinct GluK2/3 and PSD95 localization between CA3 pyramidal cells and hilar MCs. (E,F) GluK2/3 and PSD95 labeling are intense in the CA3 stratum lucidum (E). A high-magnification image confirms their extensive overlap (F). $(\mathbf{G}, \mathrm{H})$ A MC, which is identified as a calretinin-positive $\left(\mathrm{G}_{1}\right.$, blue $)$ and GFP-negative $\left(\mathrm{G}_{2}\right.$, white $)$ cell in GAD67/GFP mice, shows weak labeling for GluK2/3 on its dendrites (red, arrows in $\mathrm{H}$ ). Note that such GluK2/3 puncta are neither overlapped nor associated with PSD95 signal $\left(\mathrm{H}_{2}\right.$, green). (I-L) Distinct GluK2/3 and Neto1 localization between CA3 pyramidal cells and hilar MCs. (I,J) Intense GluK2/3 and Neto1 labeling in the CA3 stratum lucidum (I). A high-magnification image shows Neto1 labeling is only observed on GluK2/3-positive puncta $(J)$. (K,L) A MC shows weak labeling for GluK2/3 on its dendrites (red, arrows in $L$ ) but lacks Neto1 labeling ( $L_{2}$, green). DG, dentate gyrus; GrDG, granule cell layer of the DG; MoDG, molecular layer of the DG; SL, stratum lucidum; SP, stratum pyramidale; SR, stratum radiatum. Scale bars, (A,D) $100 \mu \mathrm{m} ;(\mathbf{E}, \mathbf{F}, \mathbf{I}, \mathbf{J}, \mathbf{G}, \mathbf{K})$ $10 \mu \mathrm{m} ;(\mathbf{H}, \mathbf{L}) 2 \mu \mathrm{m}$.

Figure 5. GluK2/3 in hilar MCs are enriched at non-synaptic sites. (A,B) A large MF terminal characteristically forms multiple asymmetric synapses (arrowheads) with TEs (blue) of CA3 pyramidal cells. In wild-type (WT) mice, metal particles for GluK2/3 (arrows) are prevalent on PSD (A). Postsynaptic labeling is absent in GluK2 KO mouse (B). (C-F) MCs (green) contact with large MF terminals in the hilus of the DG. In WT mice, MF synapses on MC spines are rarely labeled for GluK2/3; occasionally, non-synaptic membrane on dendritic shaft has low but significant labeling (C). Neither synaptic nor extrasynaptic labeling is observed in GluK2 KO mice (D). MCs occasionally have thin dendrites originating from soma $(E)$ and contact with large MF terminal via 
1 multiple spines (F). Note that metal particle for GluK2/3 (arrows) leave postsynaptic membrane

2 unlabeled. (G) Average and individual data points for the density of metal particles for GluK2/3

3 on CA3 pyramidal cells (blue symbols, left axis) and hilar MCs (green symbols, right axis). Note

4 low but significant non-synaptic labeling on MCs. Edges of PSD are indicated by pairs of

5 arrowheads. Number of measured profiles (\#) and membrane length $(\mathrm{mm})$ are indicated in

6 parentheses. Dunn's post Test. * $p<0.05 ; * * p<0.01 ; * * * p<0.001$. Scale bars, (A-D,F) $200 \mathrm{~nm}$;

7 (E) $1 \mu \mathrm{m}$.

Fig 6. MC-KARs can be activated by endogenous glutamate. (A) Representative experiments showing the effect of TBOA (100 $\mu \mathrm{M}$ - left), dihydrokainic acid (DHK $100 \mu \mathrm{M}$ - middle) mice and DHK in GluK2 KO mice on MCs holding current. Recordings conditions were as in Fig.1. Activation of KARs was confirmed by application of the AMPAR/KAR antagonist NBQX $(25 \mu \mathrm{M})$ at the end of the recording. NBQX was not applied in GluK2 KO as no inward current was detected. (B) Quantification of the effect of TBOA (left) and DHK (right) on MCs holding current. Dots represent the average current of 2 minutes of recording taken 2 minutes before DHK/TBOA application 16 (baseline), 2 minutes before NBQX application (+DHK/TBOA), and 2 minutes at the end of NBQX 17 application (+NBQX). Connected dots represent the same cell. (C) Summary plot of the 18 experiments shown in (B) and in the DHK GluK2 KO dataset. (TBOA: 61.24 $\pm 18.61 \mathrm{pA}$; * $\mathrm{p}=$ 190.02173 one sample t Test; DHK: $28.06 \pm 7.4$ pA; $n=3 a / 6 c ; n=4 a / 6 c ;$ DHK GluK2 KO: $-8.5 \pm$ 7.47; $n=3 a / 4 c ;$ DHK vs DHK GluK2 KO mice: * $p=0.0105$ two sample t Test). Data are presented 21 as mean \pm S.E.M. 
A
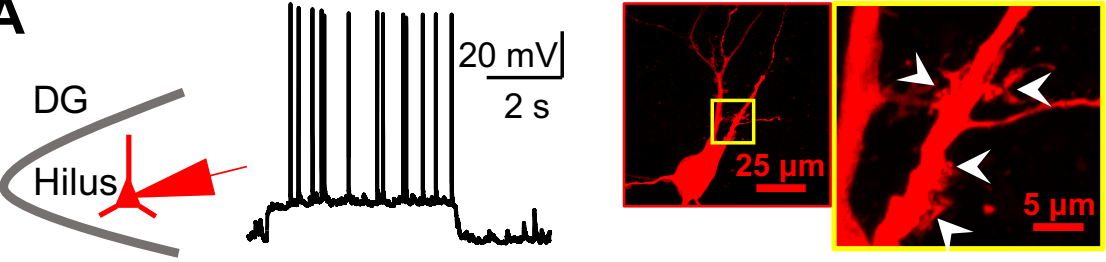

B

$\mathrm{MC}$
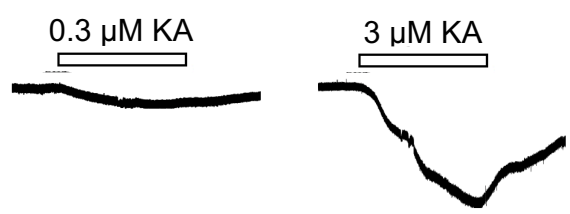

GC

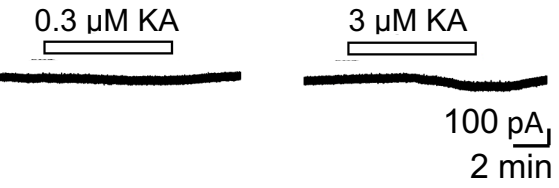

C

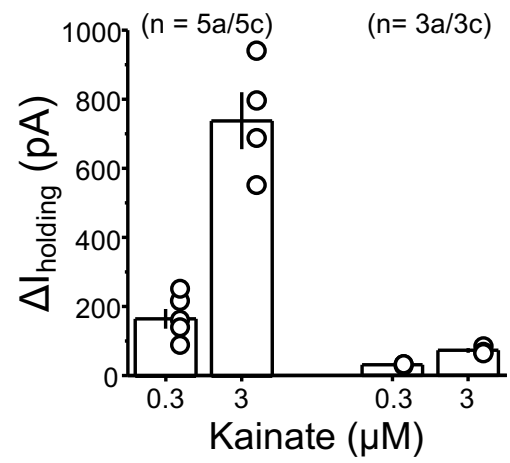

D

E
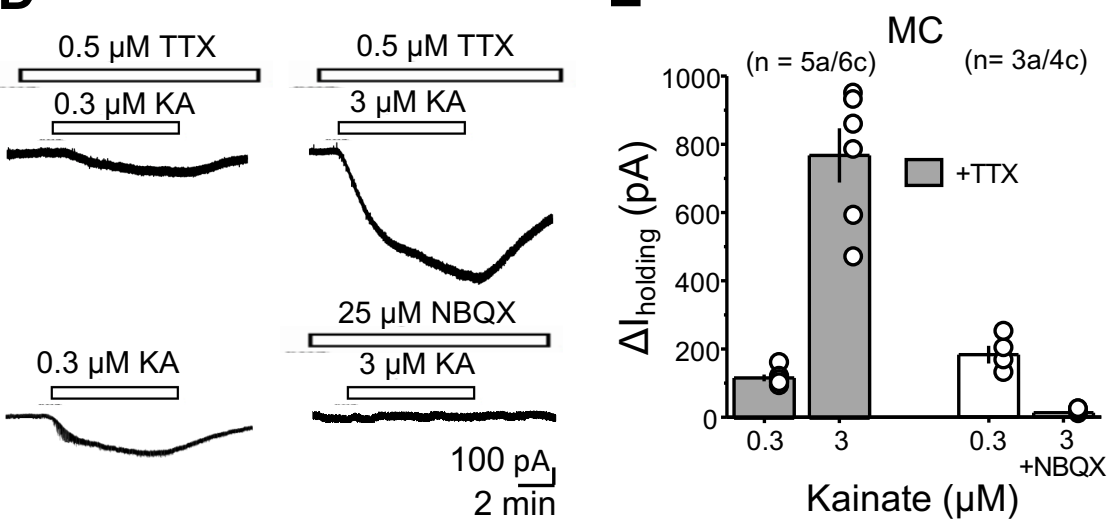

F

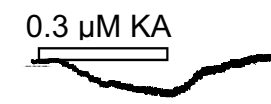

WT

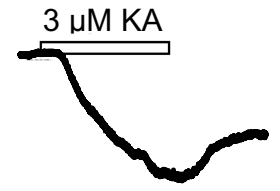

$\mathrm{KO}$

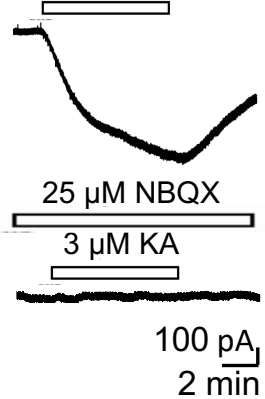

G

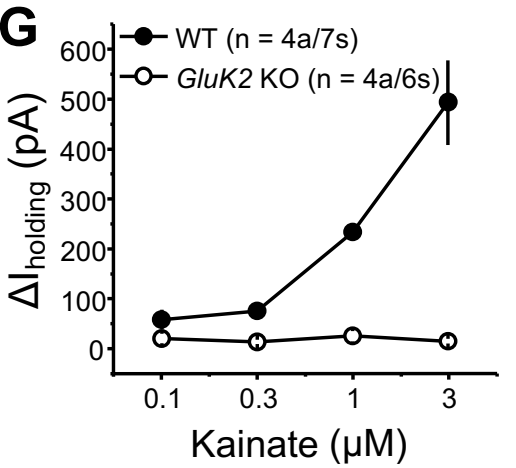

Figure 1 

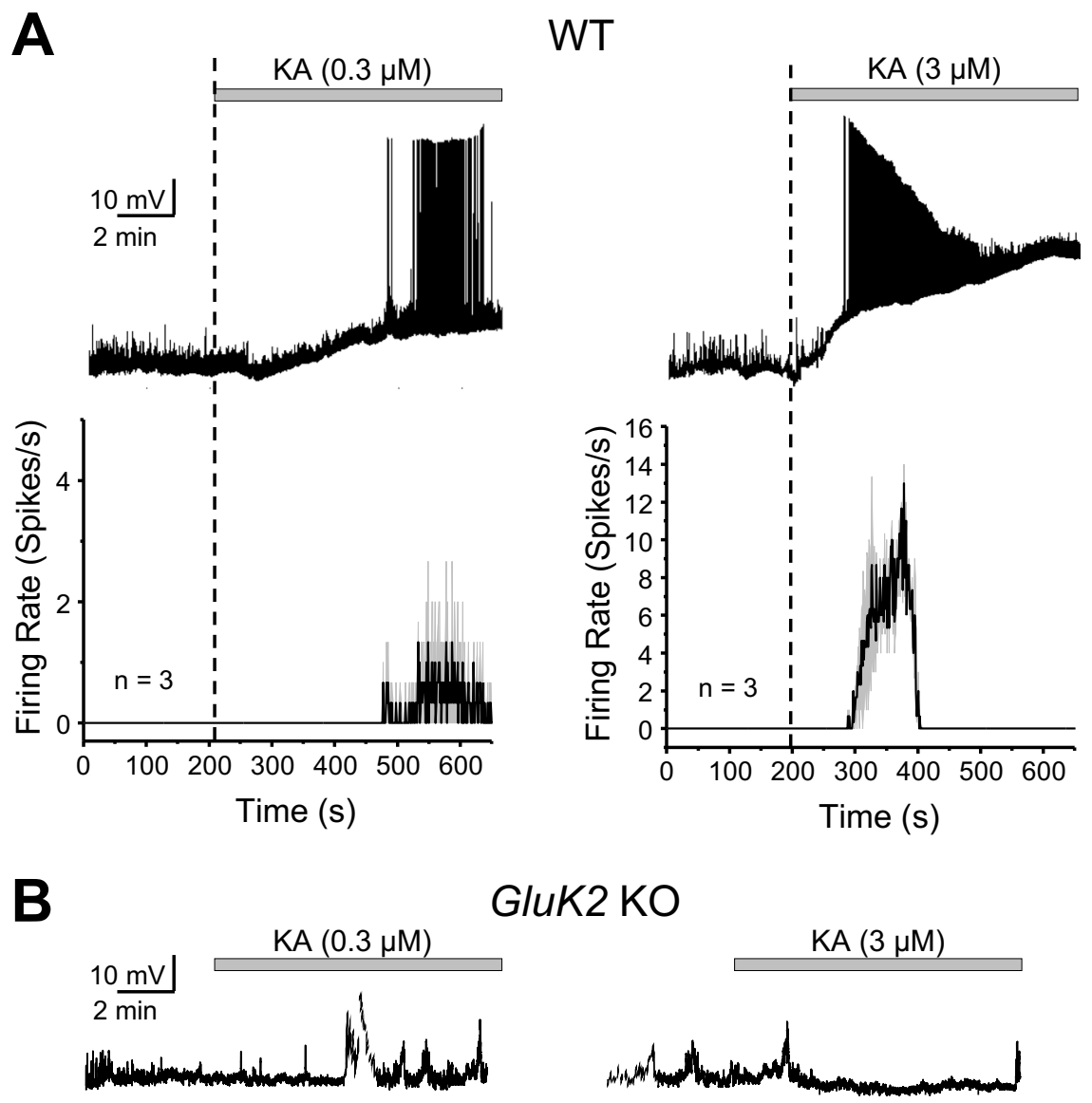

GluK2 KO

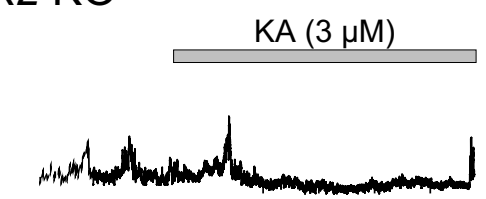

Figure 2 
A

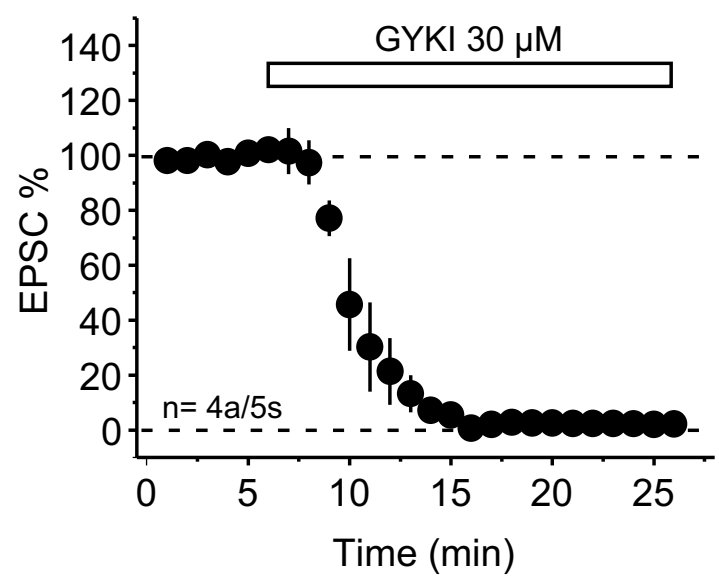

C

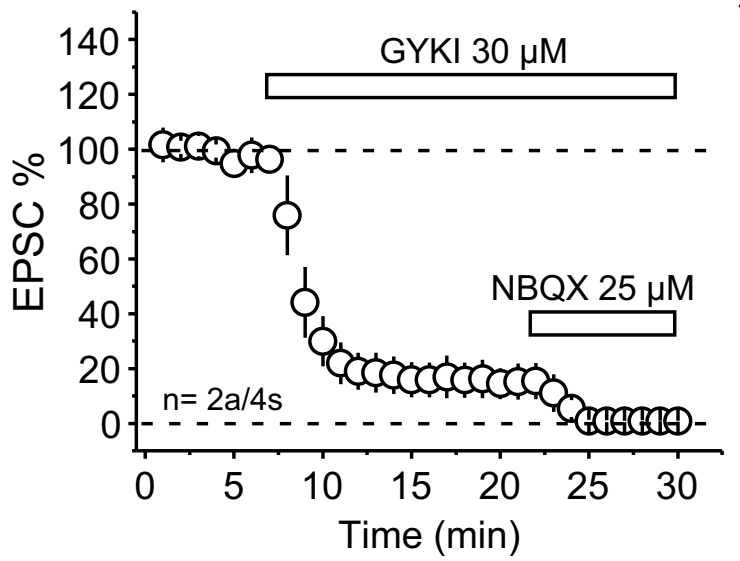

B
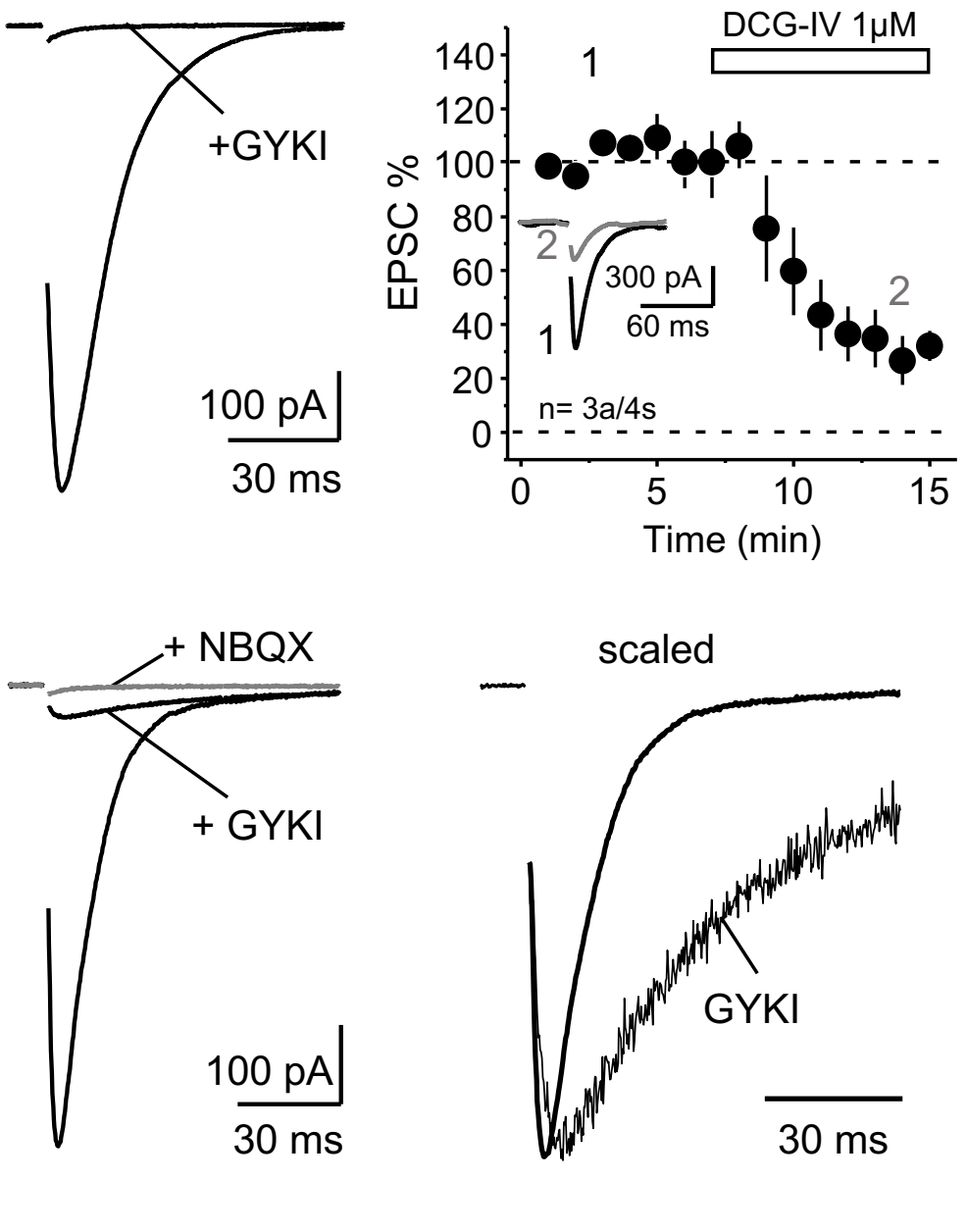

scaled

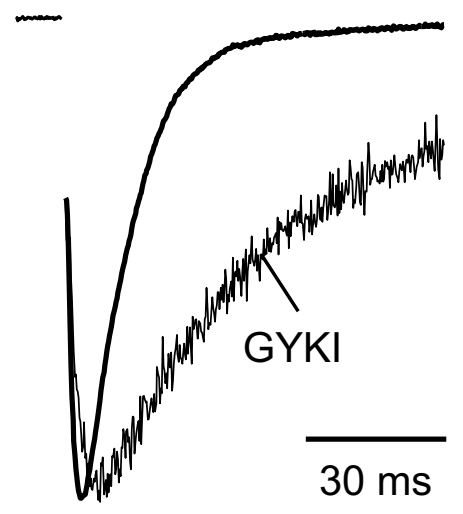

Figure 3 


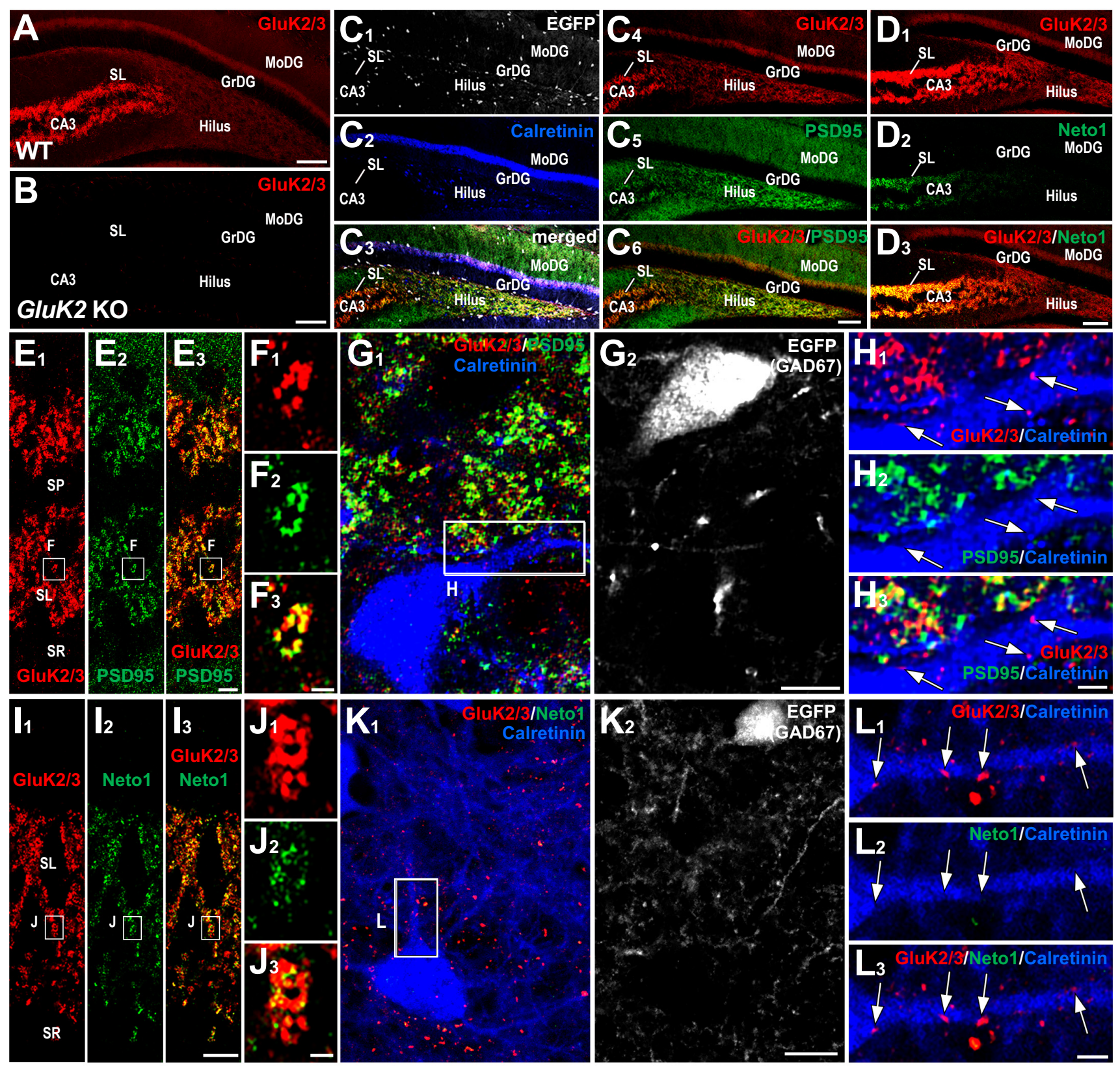

Figure 4 


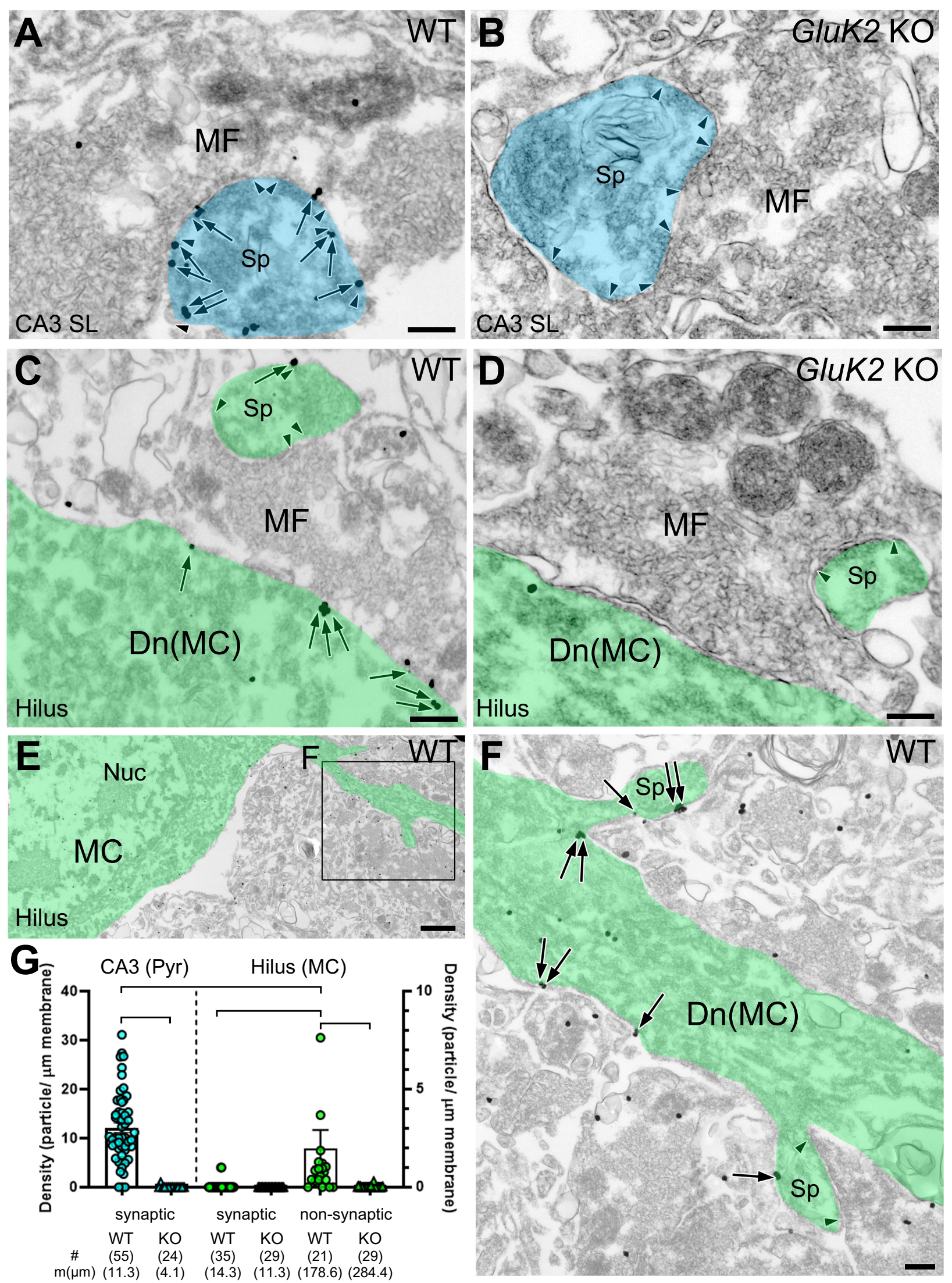

Figure 5 


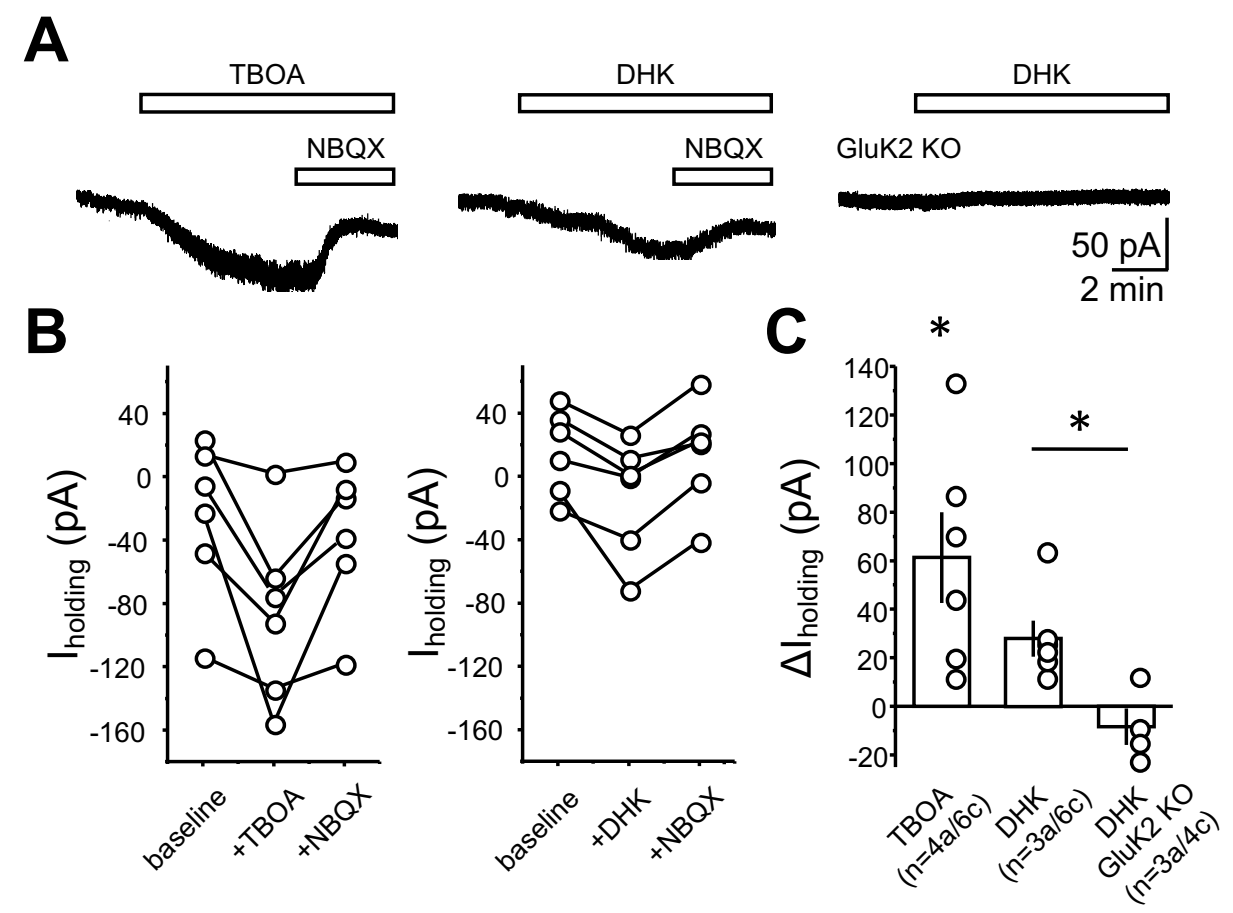

Figure 6 